The Egyptian Journal of Hospital Medicine (April 2019) Vol. 75 (4), Page 2563-2569

\title{
Ologen Implant Application in Subscleral Trabeculectomy versus Non-Penetrating Deep Sclerectomy in Management of Primary Open Angle Glaucoma: A Prospective Randomized Study \\ Mohammed Ahmed El Malah, Asaad Nooreldin*, Mohamed Elmoddather, and Mahmoud Said El Labny \\ Department of Ophthalmology, Faculty of Medicine, Al-Azhar University (Assuit), Egypt \\ *Corresponding Author: Asaad Nooreldin, E-mail: asaad_nooreldin@yahoo.com, Mob: +201026366024
}

\begin{abstract}
Background: trabeculectomy and deep sclerectomy (DS) aim to lower intraocular pressure (IOP) in cases of medically uncontrolled primary open angle glaucoma (POAG). The application of Ologen implant is thought to increase the success rate of both procedures.

Objective: to compare the application of Ologen implant in trabeculectomy versus deep sclerectomy in patients with uncontrolled POAG. Patients and Methods: this was a follow-up randomized clinical comparative trial included 30 eyes of 26 patients with uncontrolled POAG. They were randomly assigned to two equal groups ( $\mathrm{n}=15$ eyes): group (A) underwent trabeculectomy and group (B) underwent deep sclerectomy. Both procedures were augmented with Ologen implant. All patients were subjected to full history taking and complete ophthalmologic examination. Postoperatively, patients were followed up at 6 months. Outcome and complications were assessed.

Results: both groups experienced significant reduction in IOP after 6 months postoperative; preoperative and postoperative values were $22.8 \pm 3.73 \mathrm{mmHg}$ and $11.07 \pm 2.63 \mathrm{mmHg}$, respectively in group (A) and $20.13 \pm 2.26 \mathrm{mmHg}$ and $13.53 \pm 2.61 \mathrm{mmHg}$, respectively in group $\mathrm{B}, \mathrm{P} \leq 0.01$. The complete success was $93.0 \%$ in group (A) and $80.0 \%$ in group $(\mathrm{B}),(\mathrm{P}=0.475)$. Group $(\mathrm{A})$ had significantly higher frequency of postoperative complications compared to group $\mathrm{B}(\mathrm{P} \leq 0.01)$.

Conclusion: the application of Ologen implant in both trabeculectomy and deep sclerectomy is effective for IOP reduction and it resulted in better operative success in patients with POAG. Also, deep sclerectomy using Ologen implant is a good and safe alternative to trabeculectomy in patients with POAG, but our obtained results need to be supported by subsequent studies.
\end{abstract}

Keywords: Ologen implant, Subscleral Trabeculectomy, Deep Sclerectomy, Primary open angle Glaucoma.

\section{INTRODUCTION}

Glaucoma is a broad term that entails a diverse range of disorders causing progressive visual field loss and ultimately optic nerve atrophy; it is the main cause of irreversible loss of vision globally, even with appropriate treatment ${ }^{(\mathbf{1})}$. The total number of suspected cases of glaucoma is about 70 million worldwide and unfortunately approximately $10 \%$ of people with glaucoma who receive proper treatment still experience loss of vision ${ }^{(2)}$. Primary open angle glaucoma (POAG) is the commonest form of glaucoma, it accounts for $19 \%$ of all blindness among African Americans compared to 6\% in Caucasians ${ }^{(3)}$. Unlike secondary glaucoma, POAG lacks identifiable risk factors; however, elevated intraocular pressure (IOP) is a known risk factor for $\mathrm{POAG}^{(4)}$.

If medical treatment failed to achieve adequate control of IOP and other ocular effects of POAG, surgical treatment is mandatory. Surgical options include subscleral trabeculectomy which is the most commonly performed procedure which allows drainage of $\mathrm{AH}$ from within the eye to underneath the conjunctiva where it is absorbed ${ }^{(5)}$. Non-penetrating deep sclerectomy (DS) is another choice characterized by its non-invasive nature and the subsequently lower rate of operative complications such as sudden hypotony which is frequently associated with trabeculectomy ${ }^{\left({ }^{(6}\right)}$.

The Ologen implant was developed aiming at replacing Mitomycin $\mathrm{C}$ (MMC) for glaucoma surgeries, it is a disc-shaped biodegradable collagen matrix that was designed to avoid excessive scarring after trabeculectomy ${ }^{(7)}$. Subconjunctival insertion of Ologen implant intraoperatively provides a mechanical separation between the conjunctiva and the episcleral space and prevents adhesions between them $^{(8)}$.

\section{Objective of the study:}

The objective of this study is to compare the application of Ologen implant in trabeculectomy versus deep sclerectomy in patients with uncontrolled POAG.

\section{PATIENTS AND METHODS}

This interventional follow-up randomized clinical comparative trial was conducted at Al-Azhar University Hospital (Assiut), Egypt from August 2017 to June 2018. The study included 30 eyes from 26 patients.

Inclusion criteria: established diagnosis of POAG with IOP >21 mmHg, age above 40 years and 
progressive cupping and visual field changes despite maximal antiglaucoma medications.

Exclusion criteria: patients were excluded if they have corneal or ocular surface infection, dense media opacity preventing proper examination, other types of Glaucoma, previous ocular surgery (such as phaco, vitrectomy, etc.) or conjunctival scarring disorders. The studied patients were randomly assigned to two equal groups as follow: group (A): Underwent Trabeculectomy augmented by Ologen implant or group (B): Underwent Deep sclerectomy augmented by Ologen implant.

All included patients received complete ocular and systemic assessment in terms of complete history tacking and complete ophthalmic examination including best corrected visual acuity (BCVA) (Landolt broken rings chart), manifest refraction, anterior segment assessment (by Slit lamp), and IOP measurement (Goldman applanation tonometer) from 10 am to $2 \mathrm{pm}$ to eliminate the effect of diurnal variation. The anterior segment was evaluated using the slit lamp. AC angle was assessed by Goldmann 3 mirror contact lens. Fundus biomicroscopy was used to assess retina and optic disc by $+90 \mathrm{D}$ Volk noncontact lens. Systemic examination included blood pressure measurement, ECG and laboratory investigations (Random blood glucose, CBC, coagulation profile, liver and kidney functions).

\section{Surgical techniques:}

Retro-bulbar anesthesia was used in all cases in both groups (4 cc Lidocaine $2 \%+2 \mathrm{cc}$ Hyaluronidase $1500 \mathrm{IU} / \mathrm{ml}$ ). In some patients, corneal traction suture was applied to upper limbus using Vicryl $6 / 0$ to rotate the eyeball downward and to expose sufficient scleral area. Conjunctival flap with fornix-based about $6 \mathrm{~mm}$ straddling on both sides of 12 o'clock meridian at superior limbus was created by Westcott conjunctival scissor (Figure 1). The conjunctiva was incised as close as possible to the limbus. Blunt dissection of the subconjunctival space and overlying Tenon's capsule was carried out to expose the underlying sclera and avoid superior rectus insertion. A trial to control bleeding was first attempted by microsponge application, and if failed, gentle electro-cautery was applied.

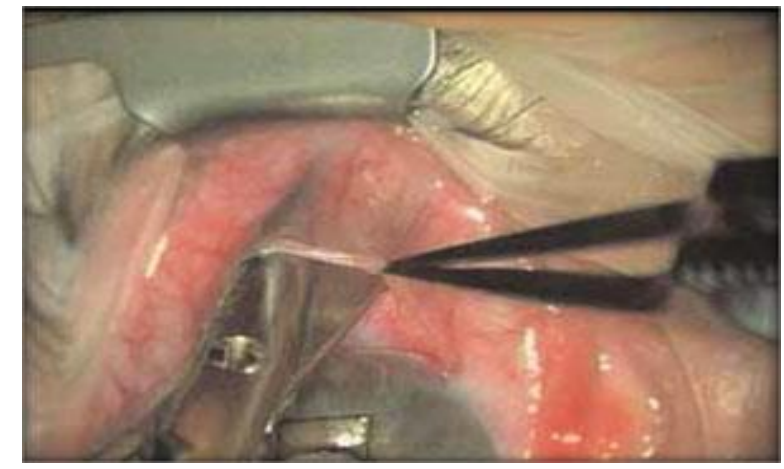

Figure (1): Dissection of the conjunctiva.

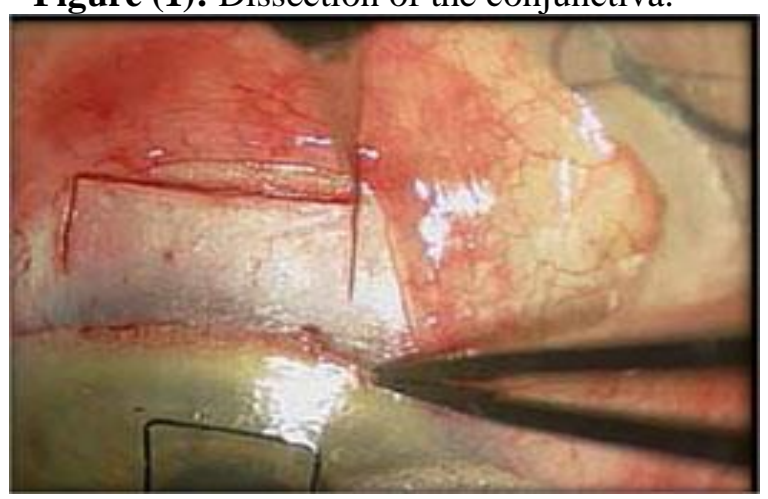

Figure (2): Rectangular superficial sclera flap.

In Group A (Trabeculectomy): Regarding scleral flap dissection, quadrangular scleral flap (about $4 \times 4$ $\mathrm{mm}$ ) was performed by a crescent knife (Dual bevel, $1.2 \mathrm{~mm}$ ). It included half of the scleral thickness as seen in (Figure 2). Dissection was advanced for about $1 \mathrm{~mm}$ in the clear cornea. A corneal side port was created using 20 gauge micro vitreo-retinal blade (MVR blade) before opening the globe. A block of tissue at the corneo-scleral junction (about $1 \mathrm{~mm} \times 2$ $\mathrm{mm}$ ) was incised by MVR blade. The iris was grasped near its root with toothed forceps and retracted through the sclerotomy. A wide basal peripheral iridectomy was performed by Vannas scissor as seen in (Figure 3).

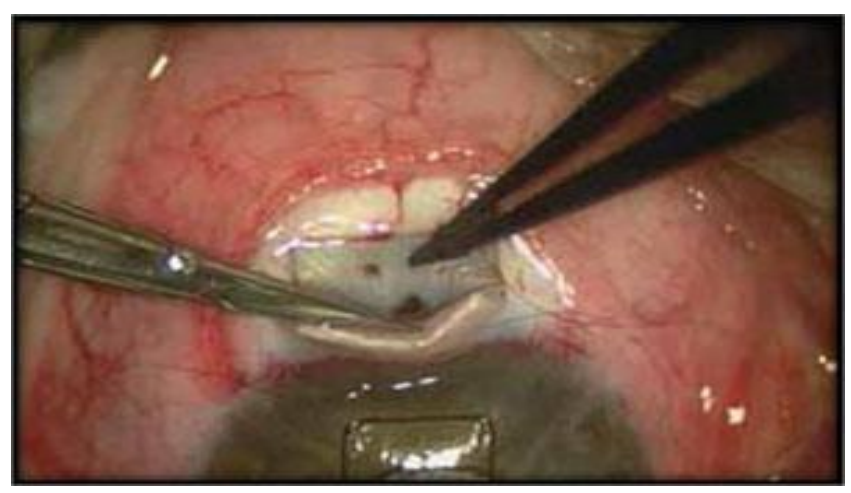

Figure (3): Peripheral iridectomy. 


\section{Mohammed Ahmed El Malah et al.}

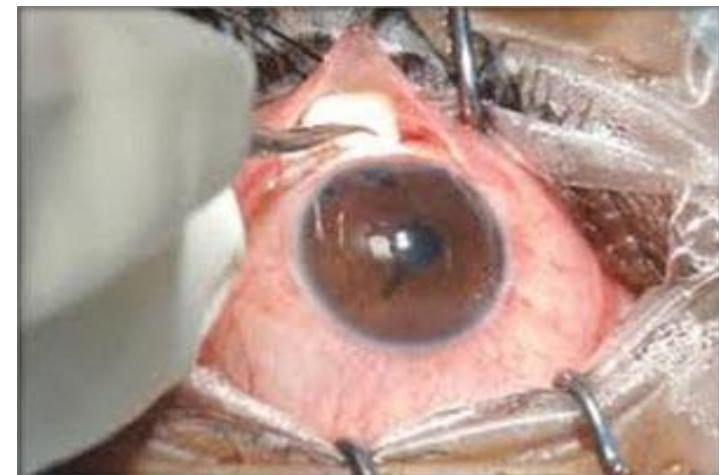

Figure (4): Ologen implant and conjunctival closure.

Ologen $(6 \mathrm{~mm} \times \mathrm{x}$ 2) is trimmed to be implanted beneath the scleral flap and the remaining part is implanted subconjunctivally as in (Figure 4). Suturing the scleral flap was performed using 2 interrupted 10/0 nylon stitches and closure of the conjunctiva was performed using 8/0 vicryl stitches. Bleb titration with BSS was achieved from the corneal incision side port and the AC was reformed. The bleb was formed on table. Subconjunctivaly, $0.5 \mathrm{cc}$ dexamethasone $(2 \mathrm{mg} / \mathrm{ml})$ and $0.5 \mathrm{cc}$ gentamycin $(80 \mathrm{mg} / \mathrm{ml})$ were injected into the inferior fornix using 27 gauge insulin syringes.

- In Group B (DS): A limbal based superficial $5 \times 5$ $\mathrm{mm}$ scleral flap of one-third thickness was fashioned and extended $1.5 \mathrm{~mm}$ into clear cornea as in (Figure 5-1,2). A second deep scleral flap was dissected as in (Figure 5-2) leaving only a 50-100 $\mu \mathrm{m}$ thickness scleral bed. This flap should be $4 \times 4 \mathrm{~mm}$ leaving a step for closure of the superficial flap. Schlemm's canal (SC) gets deroofed as the dissection is advanced anteriorly. The Trabeculum-Descemet's membrane (TDM) was fashioned by extending the dissection up to $1-1.5 \mathrm{~mm}$ into clear cornea. To avoid perforation during this part of the procedure, Descemet's membrane was gently detached using a sponge or a spatula. The radial incisions extending the deep flap into the clear cornea were done by holding a No. 11 steel blade or a $15^{\circ}$ diamond knife with the bevel up to avoid entering the anterior chamber. Once this dissection is completed the deep flap was excised using a blade or fine scissors. At this stage, $\mathrm{AH}$ was percolating through the trabeculum. Once dried, the inner wall of SC and the juxtacanalicular could be grabbed by fine forceps and peeled off the underlying trabeculum.

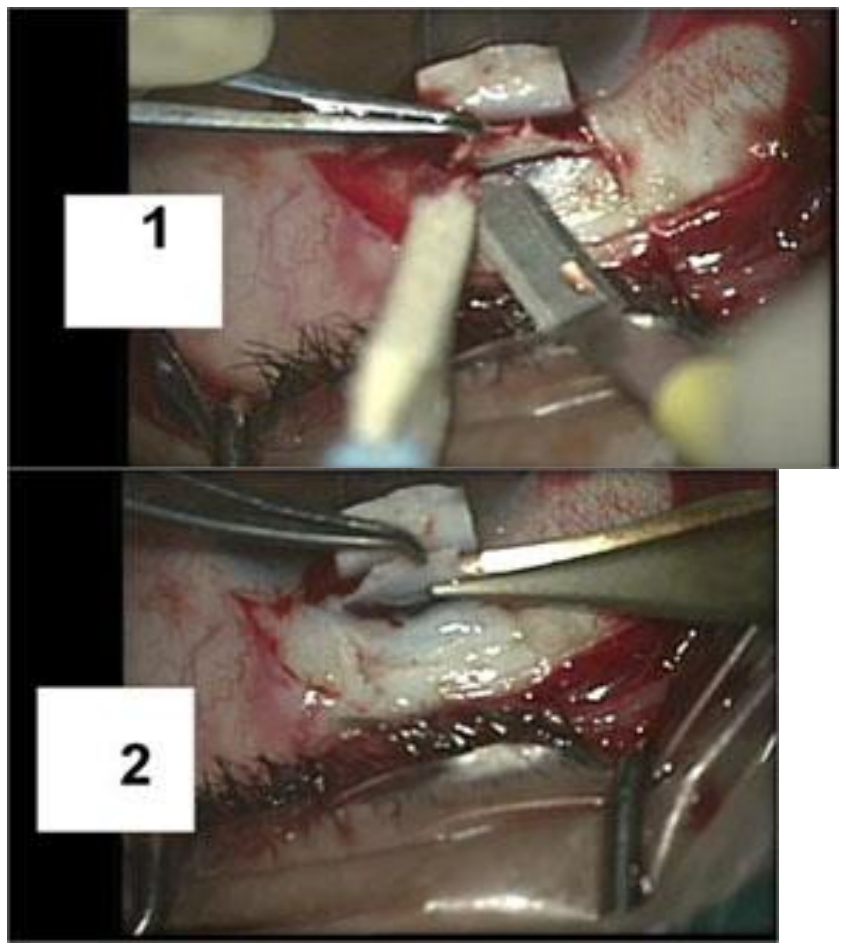

Figure (5-1 \& 2): Dissection and excision of the deep sclera flap.

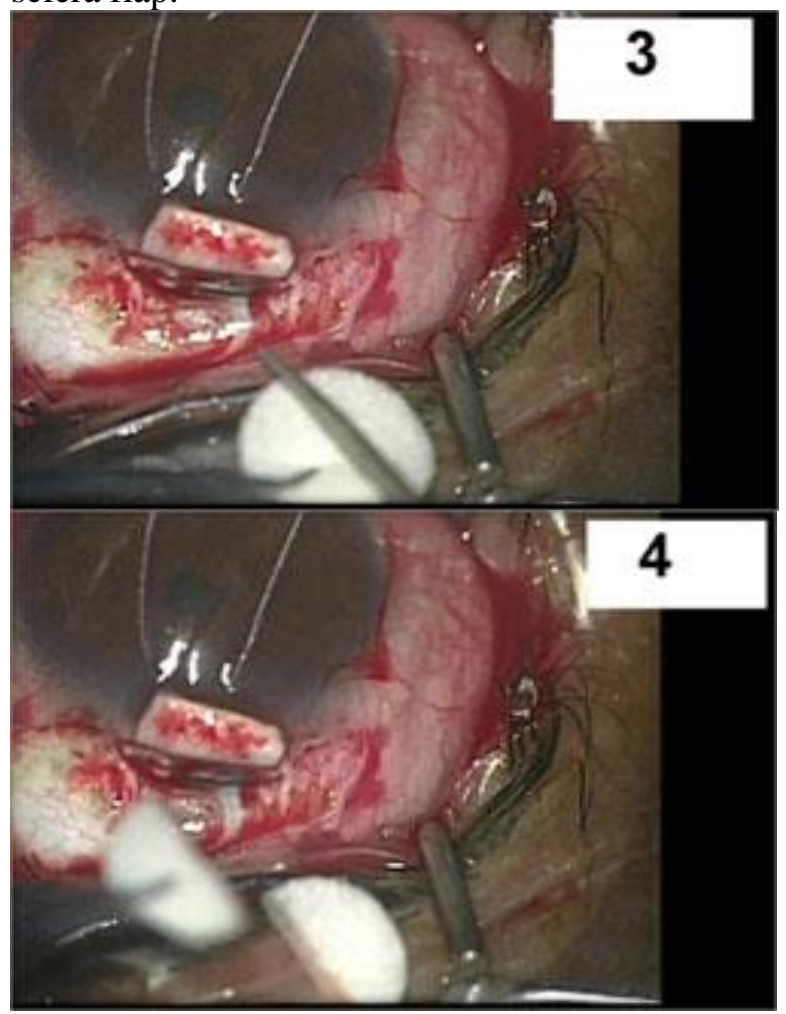

Figure (6-3 \& 4): Ologen implanted.

Ologen $(6 \mathrm{mmx} 2)$ was trimmed (Figure 6-3,4) to be implanted beneath the scleral flap (Figure 7-5) and the remaining part was implanted subconjunctivally as in (Figure 7-6). The scleral flap was 
sutured using 2 interrupted 10/0 nylon stitches at the angle of sclera flap. Stiches were then impeded under the flap. Closure of the conjunctiva was performed using $8 / 0$ vicryl stitches. $0.5 \mathrm{cc}$ dexamethasone (2 $\mathrm{mg} / \mathrm{ml})$ and $0.5 \mathrm{cc}$ gentamycin $(80 \mathrm{mg} / \mathrm{ml})$ were injected into the inferior fornix using 27 gauge insulin syringes. Topical antibiotics, steroids and cyloplegic eye drops were used in both surgeries.

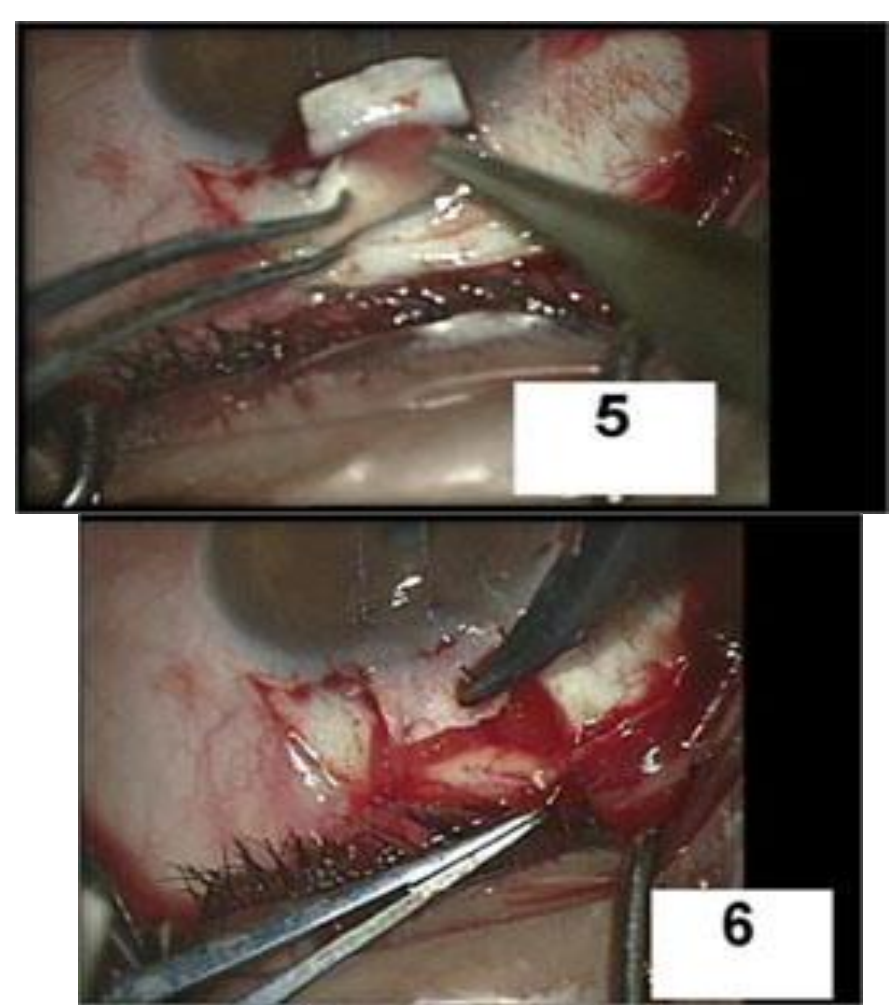

Figure (7-5 \& 6): The Ologen implanted under the superficial scleral flap and sutured.

Follow-up was done after 6 months postoperative. Intraoperative and postoperative complications were assessed. Regarding operative success, an IOP of $\leq 18 \mathrm{mmHg}$ and a relative reduction of $\geq 20 \%$ compared with the preoperative IOP (with no additional glaucoma surgery or medication) was considered as complete success. However, qualified success was defined as an IOP of $\leq 18 \mathrm{mmHg}$ and an additional IOP decrease of $\geq 20 \%$ compared to the preoperative IOP (also, with no additional glaucoma surgery or medication), but with one topical medication allowed.

Ethical considerations: The study protocol and all procedures performed involving human participants were approved by the Ethical Committee of the Faculty of Medicine, Al-Azhar University (Assiut), Egypt. Informed consent was obtained from all patients.

\section{Statistical analysis:}

Data were statistically analyzed using SPSS version 15 (IBM, USA). Continuous data were expressed in the form of mean \pm SD while categorical data were expressed in the form of frequency and percent. Comparisons of continuous data were performed utilizing independent and paired sample ttest, while comparisons of categorical data were done using Chi-square test or Fisher exact test as appropriate. P-value $<0.05$ was considered statistically significant, however, P-value of $<0.01$ was considered highly significant.

\section{RESULTS}

In this study, both groups were matched regarding age and sex distribution (Table 1). Both groups experienced a highly significant reduction in IOP after 6 months postoperatively (preoperative and postoperative values were $22.8 \pm 3.73 \mathrm{mmHg}$ and $11.07 \pm 2.63 \mathrm{mmHg}$, respectively in group $\mathrm{A}$ and $20.13 \pm 2.26 \mathrm{mmHg}$ and $13.53 \pm 2.61 \mathrm{mmHg}$, respectively in group $\mathrm{B}$; Table 2). However, IOP reduction rate was significantly higher in group $\mathrm{A}$. No significant differences were noticed between the studied groups regarding the preoperative and postoperative perimetric measurements (Table 2 ).

Table (1): Age and sex between the studied groups

\begin{tabular}{|c|c|c|c|c|}
\hline \multirow{2}{*}{\multicolumn{2}{|c|}{ Variable }} & \multicolumn{2}{|c|}{ Groups } & \multirow[b]{2}{*}{$\begin{array}{l}P \text {-value } \\
\text { (Sig.) }\end{array}$} \\
\hline & & $\begin{array}{l}\text { Group (A) } \\
\text { Trabeculectomy }(n=13)\end{array}$ & $\begin{array}{l}\text { Group (B) } \\
\text { Deep sclerectomy }(n=13)\end{array}$ & \\
\hline \multicolumn{2}{|c|}{$\begin{array}{l}\text { Age (year), mean } \pm \text { SD } \\
\text { Range }\end{array}$} & $\begin{array}{c}53.9 \pm 10.6 \\
40-70\end{array}$ & $\begin{array}{c}54.0 \pm 9.9 \\
40-70\end{array}$ & $0.980^{\mathrm{NS}}$ \\
\hline \multirow{2}{*}{ Gender } & Male & $7(53.8 \%)$ & $6(46.2 \%)$ & \multirow{2}{*}{$0.694^{\mathrm{NS}}$} \\
\hline & Female & $6(46.2 \%)$ & $7(53.8 \%)$ & \\
\hline
\end{tabular}

Independent sample t-test and Chi square test were used.

NS: Not significant 
Mohammed Ahmed El Malah et al.

Table (2): Preoperative and postoperative IOP and perimetric measurements in the studied groups

\begin{tabular}{|c|c|c|c|c|}
\hline \multirow{2}{*}{\multicolumn{2}{|c|}{ Variable }} & \multicolumn{2}{|c|}{ Groups } & \multirow[b]{2}{*}{$P$ value (Sig.) } \\
\hline & & $\begin{array}{c}\text { Group (A) } \\
\text { Trabeculectomy (n=15) }\end{array}$ & $\begin{array}{c}\text { Group (B) } \\
\text { Deep sclerectomy }(n=15) \\
\end{array}$ & \\
\hline \multirow{2}{*}{$\begin{array}{l}\text { Intraocular } \\
\text { Pressure (IOP) }\end{array}$} & Preoperative & $22.8 \pm 3.73$ & $20.13 \pm 2.26$ & $0.029 *$ \\
\hline & Postoperative & $11.07 \pm 2.63$ & $13.53 \pm 2.61$ & $0.015^{*}$ \\
\hline \multicolumn{2}{|c|}{$P$ value (Sig.) } & $<0.001 * *$ & $<0.001 * *$ & --- \\
\hline \multicolumn{2}{|c|}{$\%$ of IOP reduction $(\%)$} & $43.3 \pm 14.5$ & $36.9 \pm 12.6$ & $0.207^{\mathrm{NS}}$ \\
\hline \multirow{2}{*}{$\begin{array}{l}\text { Mean deviation } \\
\text { (MD) }\end{array}$} & Preoperative & $-16.06 \pm 11.16$ & $-12.98 \pm 11.27$ & $0.458^{\mathrm{NS}}$ \\
\hline & Postoperative & $-17.12 \pm 10.90$ & $-13.1 \pm 11.37$ & $0.331^{\mathrm{NS}}$ \\
\hline \multirow{2}{*}{$\begin{array}{l}\text { Pattern Standard } \\
\text { Deviation (PSD) }\end{array}$} & Preoperative & $7.21 \pm 4.18$ & $5.39 \pm 3.56$ & $0.209^{\mathrm{NS}}$ \\
\hline & Postoperative & $6.41 \pm 3.46$ & $6.02 \pm 3.67$ & $0.766^{\mathrm{NS}}$ \\
\hline
\end{tabular}

Independent and paired sample t-tests were used, NS: Not significant, *: Significant $(\mathrm{P}<0.05)$, **: Significant $(\mathrm{P}<0.01)$

The results showed comparable operative success rates in both groups $(100 \%$ in group A vs. $93.3 \%$ in group $\mathrm{B}, \mathrm{P}=0.475)$, Table $\mathbf{3} \&$ figure $\mathbf{8}$. The intraoperative complications were minimal in both groups (one case was recorded in each group); only single case of intraoperative hyphema occurred for which $\mathrm{AC}$ wash was done with some residual at the first day postoperative and complete clearance at the first week postoperative. Regarding postoperative complications, trabeculectomy group (group A) had significantly higher complication rate compared to DS group "group B" (93.3\% vs. 6.7\%), $(\mathrm{P}<0.001)$, group $(\mathrm{A})$ showed a significantly higher rate of reaction and shallow AC (Table 3 \& figure 9). In addition, the number and function of postoperative conjunctival blebs were almost similar between groups. Moreover, the need for postoperative medical treatment was restricted to 1 and 3 patients in groups $\mathrm{A}$ and $\mathrm{B}$, respectively with no significant difference (Table $\mathbf{3}$ ).

Table (3): Operative and post-operative outcome between the studied groups

\begin{tabular}{|c|c|c|c|c|}
\hline \multirow{2}{*}{\multicolumn{2}{|c|}{ Variable }} & \multicolumn{2}{|c|}{ Groups } & \multirow[b]{2}{*}{$\begin{array}{c}P \text { value } \\
\text { (Sig.) }\end{array}$} \\
\hline & & \multirow{2}{*}{$\begin{array}{c}\begin{array}{c}\text { Group (A) } \\
\text { Trabeculectomy } \\
(\mathbf{n = 1 5 )} \text { No. }(\%)\end{array} \\
14(93.3)\end{array}$} & \multirow{2}{*}{$\begin{array}{c}\begin{array}{c}\text { Group }(\mathbf{B}) \\
\text { Deep sclerectomy } \\
(\mathbf{n = 1 5}) \text { No. }(\boldsymbol{\%})\end{array} \\
12(80.0)\end{array}$} & \\
\hline Operative success & Complete success & & & \multirow{3}{*}{$0.475^{\mathrm{NS}}$} \\
\hline & Qualified success & $1(6.7)$ & $2(13.3)$ & \\
\hline & Failure & $0(0.0)$ & $1(6.7)$ & \\
\hline \multicolumn{2}{|c|}{ Operative complications } & $1(6.7)$ & $1(6.7)$ & $1.000^{\mathrm{NS}}$ \\
\hline \multicolumn{2}{|l|}{ Hyphema } & $1(6.7)$ & $0(0.0)$ & $0.316^{\mathrm{NS}}$ \\
\hline \multicolumn{2}{|l|}{ Puncture of the TDM } & $0(0.0)$ & $1(6.7)$ & $0.316^{\mathrm{NS}}$ \\
\hline \multicolumn{2}{|c|}{ Postoperative complications } & $14(93.3 \%)$ & $1(6.7)$ & $<0.001 * *$ \\
\hline \multicolumn{2}{|l|}{ Hyphema } & $1(6.7)$ & $0(0.0)$ & $0.316^{\mathrm{NS}}$ \\
\hline \multicolumn{2}{|l|}{ Reaction } & $5(33.3)$ & $0(0.0)$ & $0.016^{*}$ \\
\hline \multicolumn{2}{|l|}{ Hypotony } & $2(13.3)$ & $1(6.7)$ & $0.553^{\mathrm{NS}}$ \\
\hline \multicolumn{2}{|l|}{ Shallow AC } & $4(26.7)$ & $0(0.0)$ & $0.034 *$ \\
\hline \multicolumn{2}{|l|}{ Complicated cataract } & $2(13.3)$ & $0(0.0)$ & $0.150^{\mathrm{NS}}$ \\
\hline \multirow{4}{*}{$\begin{array}{l}\text { Conjunctival blebs } \\
\text { after six months }\end{array}$} & Functioning Blep & $12(80.0)$ & $13(86.6)$ & \multirow{4}{*}{0.829} \\
\hline & Cystic Bleb & $2(13.3)$ & $1(6.7)$ & \\
\hline & Encapsulated Bleb $^{\#}$ & $0(0.0)$ & $0(0.0)$ & \\
\hline & No Bleb & $1(1.7)$ & $1(1.7)$ & \\
\hline \multirow{3}{*}{$\begin{array}{l}\text { Postoperative need for } \\
\text { glaucoma therapy PSD }\end{array}$} & No & $14(93.3)$ & $12(80.0)$ & \multirow{3}{*}{$0.340^{\mathrm{NS}}$} \\
\hline & Monotherapy & $1(6.7)$ & $1(6.7)$ & \\
\hline & Dual therapy & $0(0.0)$ & $2(13.3)$ & \\
\hline
\end{tabular}

Chi square or Fisher exact test was used as appropriate. "\#: Not included in statistical analysis,

NS: Not significant, *: Significant $(\mathrm{P}<0.05), * *$ : Highly significant $(\mathrm{P}<0.001)$ 


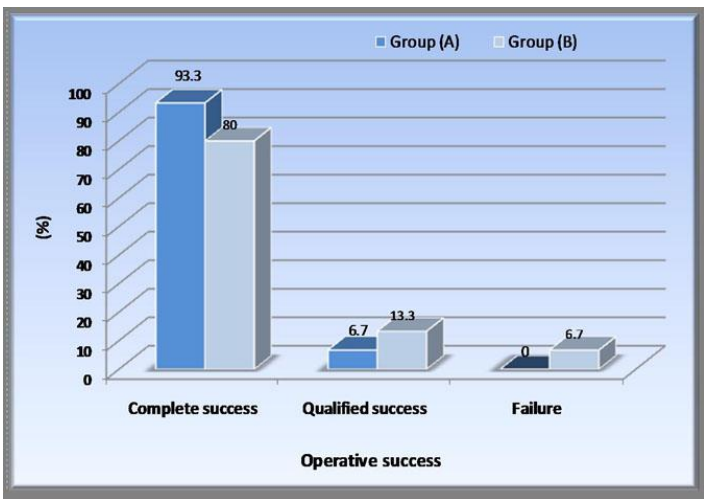

Figure (8): Success rate between groups.

\section{DISCUSSION}

Trabeculectomy has been the most commonly performed surgical approach for lowering IOP until Non-penetrating deep sclerectomy was introduced ${ }^{(\mathbf{9})}$. Indeed, the objective when converting from trabeculectomy to deep sclerectomy should be to obtain the same IOP control but with fewer complications related to hypotony ${ }^{(\mathbf{1 0})}$.

In animal studies, Ologen implant has been tested and resulted in the prevention of the collapse of the subconjunctival space. Also, the application of Ologen with trabeculectomy caused random collagen deposition and formation of microcyst ${ }^{(\mathbf{1 1 1}, 12)}$. The commonest advantage of the biodegradable implant is decreasing early postoperative scarring ${ }^{(11)}$. This study was designed to compare the application of Ologen implant in trabeculectomy versus deep sclerectomy in patients with uncontrolled POAG. In the published literature, only one of the studied procedures; trabeculectomy with Ologen-( ${ }^{(8)}$ or deep sclerectomy with Ologen-(13) implant application was compared with a control group or with another procedure ${ }^{(7)}$. To the best of our knowledge, no study compared the two procedures with Ologen implant application.

In the present study, trabeculectomy and deep sclerectomy augmented with Ologen implant showed pronounced efficacy in IOP reduction in patients with POAG. However, trabeculectomy had better IOP reduction rates when compared with DS $(43.3 \%$ versus $36.9 \%)$. On the other hand, DS was associated with fewer complications. Likewise, IOP reduction rates in the study of Chiselita ${ }^{(\mathbf{1 3})}$ were $39.6 \%$ and $30.6 \%$ after 6 months postoperatively in trabeculectomy and DS, respectively with significantly fewer complications in the DS patients. Of note, IOP reduction rates in his study are lower the corresponding rates in our study.

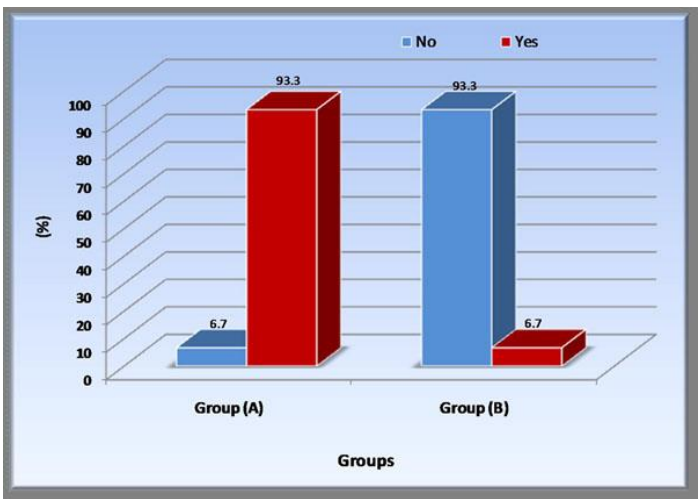

Figure (9): Complications between groups.

Clearly, this is attributed to the application of Ologen implant in our study. Similar conclusions were reported by the studies of Ambresin et $\boldsymbol{a l} .^{(14)}$ and Lamia et al. ${ }^{(15)}$. Also, in another study, Rosentreter et al. ${ }^{(16)}$ found that the Ologen application with trabeculectomy caused $43 \%$ reduction in postoperative IOP $(\mathrm{P}<0.01)$. Further, they did not report any side effects (such as translocation of the implant or conjunctival erosion) that cause by ologen. In addition, Aptel $\boldsymbol{e t} \boldsymbol{a l} .{ }^{(\mathbf{1 7 )}}$ evaluated Ologen implant augmentation in deep sclerectomy; they found that this method is effective and well-tolerated for IOP reduction.

The value of Ologen implant in reducing postoperative hypotony was reported by the study of Cillino et al. ${ }^{(18)}$ who noted that use of Ologen implant was associated with less hypotony when compared with MMC as an adjuvant in trabeculectomy. Ologen can induce a modulation of the aqueous outflow by occupying the subconjunctival space by its volume and applying a pressure on the top of the scleral flap. They also found that Ologen implant application was associated with very few antiglaucoma medications during the follow-up period.

The benefit of Ologen implant application to DS was manifested by the study of Shaarawy et al. ${ }^{(19)}$ who conducted a prospective randomized trial of 104 eyes (104 patients) with medically uncontrolled primary and secondary open angle glaucoma. They found that 48 months postoperative IOP was reduced by $40 \%$ for the DS group and by $50 \%$ for the deep sclerectomy with a collagen implant (DSCI) group. Also, complete success rate at 48 months was $34.6 \%$ for the DS group and $63.4 \%$ for the DSCI group. However, qualified success rate was $78.8 \%$ for the DS group and $94 \%$ for the DSCI group. In addition, the mean number of medications was reduced in both 
groups $(\mathrm{p}=0.001)$. They concluded that the uses of Ologen implant in Non-penetrating deep sclerectomy (NPDS) group increase the success rate, obviously lowering the IOP and lowers the need for postoperative medication.

\section{LIMITATIONS OF THE STUDY}

The present study has some limitations such as the relatively small sample size and the shorter followup period. So, it is necessary to perform further studies with a large sample size and longer follow-up.

\section{CONCLUSION}

On the basis of our observations, the application of Ologen implant in both trabeculectomy and deep sclerectomy is effective for IOP reduction (this reduction was higher in trabeculectomy group) and it resulted in better operative success in patients with POAG. Deep sclerectomy had significantly lower postoperative complications. Using of Ologen in both procedures might be better and safer than other antimetabolites due to avoiding their well reported side effects. Also, deep sclerectomy using Ologen implant is a good and safe alternative to trabeculectomy in patients with POAG, but our obtained results need to be supported by subsequent studies.

\section{References}

1. Kanski J, Bowling B (2016): Overview of glaucoma. In: Kanski's Clinical Ophthalmology: Systematic Approach, $8^{\text {th }}$ edition, Elsevier.

2. Susanna R, De Moraes CG, George A et al. (2015): Why Do People (Still) Go Blind from Glaucoma? Transl Vis Sci Technol., 4(2): 1-7.

3. Adamis AP, Shima DT (2005): The role of vascular endothelial growth factor in ocular health and disease. Retina, 25:111-118.

4. Bell JA, Talavera F, Wax MB, Roy $H$ et al. (2014): POAG Treatment and Management. Medscape J Ophthalmol., 20: 12-18.

5. Vijaya L, Manish P, Ronnie G, Shantha B (2011): Management of complications in glaucoma surgery. Indian J Ophthalmol., 59 (1): S131-S140.

6. Mendrinos E, Mermoud A, Shaarawy T (2008): Nonpenetrating Glaucoma Surgery. Survey Ophthalmology, 53: 592-630.
7. Bindlish R, Condon GP, Schlosser JD et al. (2002): Efficacy and safety of MMC in primary trabeculectomy: five-year follow-up. Ophthalmology, 109 (7):13361341.

8. He M, Wang W, Zhang X et al. (2014): Ologen implant versus MMC for Trabeculectomy: A Systemic Review and Meta-Anlysis. PLoS One, 9: e85782.

9. Liu Y, Cao J, Renard RA (2006): Low dose, subconjunctival administration of VEGF trap inhibits suture-induced corneal neovascularization and inflammation. Invest Ophthalmol Visual Sci., 47: 16-26.

10. Erdurmus M, Totan Y (2007): Subconjunctival bevacizumab for corneal neo-vascularization. Graefes Arch Clin Exp Ophthalmol., 245:1577-1579.

11. Chen HS, Ritch R, Krupin T, Hsu WC (2006): Control of filtering bleb structure through tissue bioengineering: an animal model. Invest Ophthalmol Visual Sci., 47:5310-5314.

12. Hsu WC, Ritch R, Krupin T, Chen HS (2008): Tissue bioengineering for surgical bleb defects: an animal study. Graefes Arch Clin Exp Ophthalmol., 246: 709-71 7.

13. Chiselita D (2001): NPDS versus trabeculectomy in primary open-angle glaucoma surgery. Eye, 15(2): 131132.

14. Ambresin A, Shaarawy T and Mermoud A (2002): DSCI in one eye compared with trabeculectomy in the other eye of the same patient. J Glaucoma, 11(3): 214220.

15. Lamia S, Hamid MA (2014): DS versus subscleral trabeculectomy in glaucomatous eyes with advanced visual field loss. J Egy Ophthalmol Soc., 107 (4): 277 282.

16. Rosentreter A, Schild AM, Jordan JF et al. (2010): A prospective randomised trial of trabeculectomy using mitomycin $\mathrm{C}$ vs an ologen implant in open angle glaucoma. Eye, 24: 1449-1457.

17. Aptel F, Dumas S, Denis P (2009): Ultrasound biomicroscopy and optical coherence tomography imaging of filtering blebs after deep sclerectomy with new collagen implant. Eur J Ophthalmol., 19:223-230.

18. Cillino S, Di Pace F, Cillino $G$ et al. (2011): Biodegradable collagen matrix implant VS Mitomycin-C as an adjuvant in trabeculectomy: A 24-months randomized clinical trial. Eye, 25(12):1598-1606.

19. Shaarawy T, Nguyen C, Schnyder $C$ et al. (2004): Comparative study between DS with and without collagen implant: long term follow up. B J Ophthalmol., 88: 95- 98 . 